\title{
Effect of Whey Protein Based Edible Coating on the Quality of Fresh Mutton
}

\author{
Saba Belgheisi, Reza Soltani, and Ramona Massoud
}

\begin{abstract}
Food packaging is an important discipline in the area of food technology, concerns preservation and protection of foods. The objective of this research was to determine of the effect of whey protein based edible coating on the moisture loss, sensory attributes, microbial properties and total volatile nitrogen value of fresh mutton after $0,1,3$ and 5 days at $5^{\circ} \mathrm{C}$. The moisture content, moisture loss, sensory attributes (juiciness, color and odor), microbial properties (total count and psychrophilic bacteria) and total volatile nitrogen value of the coated and uncoated samples were analyzed. The results showed that, moisture content, moisture loss, juiciness and color of the coated and uncoated samples have significant differences $(p<0.05)$ at the intervals of 0 to 1 and 1 to 3 days of storage. But no significant difference was observed at interval time 3 to 5 days of storage $(p>0.05)$. Also, there was no significant differences in the odor values of the coated and uncoated samples $(p>0.05)$. Therefore, the coated samples had consistently more moisture, juiciness and colored values than uncoated samples after $3 d$ ays at $5^{\circ} \mathrm{C}$. The results showed that, total count, psychrophilic bacteria and total volatile nitrogen of the coated and uncoated samples did not have significant differences $(p>0.05)$. Therefore whey protein based edible coating could not reduce the microbial load of fresh mutton. So, whey protein edible coating could enhance product presentation and eliminate the need for placing absorbent pads at the bottom of the trays.
\end{abstract}

Index Terms-Coating, moisture, mutton, quality, whey protein.

\section{INTRODUCTION}

Longer shelf life and better quality can be made possible by using different processing techniques such as freezing and appropriate combinations of these techniques. Several have shown that edible coatings made of protein, polysaccharide and oil-containing materials help to prolong the shelf life and preserve the attributes of edible quality. The application of edible, protective coatings and films to prolong storage life of food is not new. The barrier properties of bio-polymeric films are important when considering a suitable barrier in foods and food packaging. Protein and polysaccharide films are generally good barrier against intermediate relative humidity (RH) and good mechanical properties. Much attention has been lately paid to whey protein concentrate (WPC) films

Manuscript received March 29, 2015; revised May 21, 2015. This work was supported in part by the Standard Research Institute of Iran.

Saba Belgheisi is with the Faculty of Food Industry and Agriculture, Department of Food Science \& Technology, Standard Research Institute (SRI), Karaj P. O. Box 31745-139, Iran (e-mail: Belgheisi@standard.ac.ir).

Reza Soltani is with the Faculty of Food Industry and Agriculture, Department of Biology, Standard Research Institute (SRI), Karaj P. O. Box 31745-139, Iran (e-mail: R_Soltani@standard.ac.ir).

Ramona Massoud is with Department of Food Research and Laboratory, Standard Research Organization, Tehran, Iran (email: rm8059@yahoo.com). because they are transparent with excellent barrier properties to oxygen and flavors. Generally, meat and other foods are covered with dry particles (breaded) or dipped in liquid solutions of these particles (battering).Owing to their structural characteristics, flours, gluten, protein-based materials such as whey proteins and supportive polysaccharides structured by gum and starch are commonly used. Hydrophilic edible films contain a barrier of oxygen and carbon dioxide and suitable mechanical properties at low relative humidity. Materials that are used to make edible films are the polysaccharides and protein-based polymers. Interaction with the surrounding environment during storing and processing is decreased to a minimum by coating and it prevents spoilage. In effect, the sensorial quality of the product increases and weight loss is lowered. Edible coatings are important for sensitive foods such as meat [1]. Much attention has been lately paid to whey protein (WP) coating because they are transparent with excellent barrier properties to oxygen and flavor [2].

The aim of the study is to increase shelf life to improve the overall eating quality in terms of tenderizing and changing the taste and textural and structural properties of fresh mutton meat and to provide different alternatives to the consumers. The main objectives of this research were to determine the effects of whey protein coating on the moisture loss and sensory properties of fresh mutton.

\section{MATERIAL AND METHODS}

\section{A. Film Formation Method}

Film formulation was prepared according to $\mathrm{McHugh}$ et.al [3], Perez-Gago et.al [4], Anker et al [5] and Oses et.al [6] Aqueous solutions of $5 \%(\mathrm{w} / \mathrm{w})$ WPC were prepared and heated at $90^{\circ} \mathrm{C}$ for $30 \mathrm{~min}$. in water bath. The solutions were then cooled at room temperature and vacuum was applied to remove dissolved air. Weight glycerol $(G)$ relative to the weight of WPC originally dissolved was then added as a plasticizer for film. Then the solutions were emulsified for 10 min at $140 \mathrm{rpm}$ using a shaker. Weight mono-stearate glycerol relative to the half weight of WPC originally dissolved was then added and heated at $70^{\circ} \mathrm{C}$ for $30 \mathrm{~min}$. The solutions were then cooled down at room temperature, emulsified and homogenized for $5 \mathrm{~min}$ at $500 \mathrm{rpm}$

\section{B. Coating Fresh Mutton}

Six-pack of $1 \mathrm{Kg}$ fresh muscles of mutton, each one containing $250 \mathrm{~g}$ four muscles wrapped in cellophane with pad absorbent were purchased from the meat packaging industries from (shahrvand store Tehran, Iran) and stored at $2{ }^{\circ} \mathrm{C}$ overnight for testing (ISIRI 690 [7] and ISIRI 691[8]). After the solution formation, twelve samples were randomly 
selected and followed by immersion in formation solutions (1min). The Samples were then kept overnight in refrigerator for 1, 3 and 5 days at storage conditions with exposed surface area $\left(23 \pm 2{ }^{\circ} \mathrm{C}, \mathrm{RH} 50 \%\right)$. The interval between mutton purchase and sample coating was $<5 \mathrm{hr}$. The control samples were wrapped in cellophane in retail plastic trays with placing absorbent pads at the bottom of trays.

\section{Moisture Loss Determination}

The water loss was estimated as described by Lu et al. [9]. The percentage weight loss relative to the initial weight was calculated by weighing the samples in triplicate. Moisture contents of coated fish were determined by two different methods to evaluate the water-holding capacity of meat both without and with coating

\section{Sensory Attributes Determination}

A panel of 8 trained personal from The National Nutrition and Food Technology Research Institute (Tehran, Iran) evaluated the color, odor and juiciness of coated and uncoated fresh mutton samples according to methods of Bell et.al [10] for color, Gill et.al [11] for odor and Zabik et al. [12] for juiciness.

\section{E. Total Volatile Nitrogen (TVN) and Microbial Properties Determinations}

Preparation of samples was performed based on ISIRI 690 [7], preparation of homogenous samples was performed based on ISIRI 691 [8] and Preparation of dilution samples was performed based on ISIRI 356 [13]. Also total count and psychotrophic micro-organisms determination were performed based on ISIRI 5272 [14] and ISIRI 2629 [15], respectively. Total volatile nitrogen (TVN) determination was performed based on AOAC [16]. The TVN is related to protein breakdown and can be determined and it is a detailed microbiological investigation into meat quality occupies several days.

\section{F. Statistical Analysis}

SPSS version 15 was used for all statistical analyses. The using General Linear Model with replication measurement were tested and significance level of were applied $(\alpha=0.05)$.

\section{RESULT AND DISCUSSION}

Fig. 1 shows the mean moisture values of the coated and uncoated samples during $0,1,3$ and 5 days of storage.

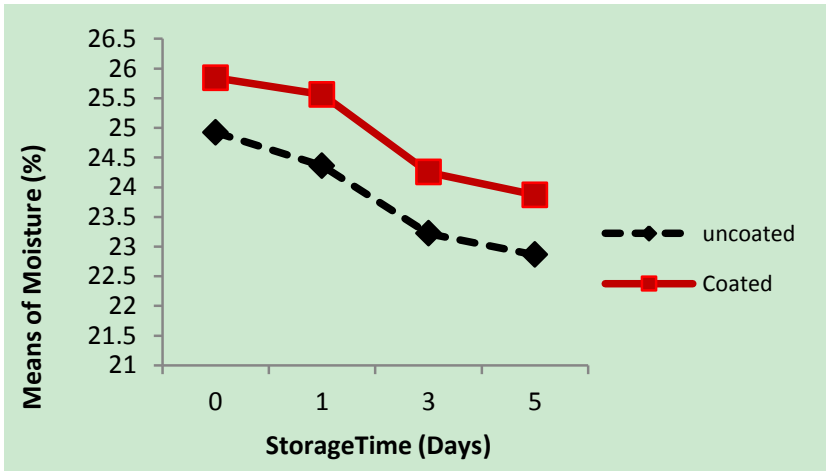

Fig. 1. Mean of moisture values in coated and uncoated samples during5 days of cold storage.
The coated samples had consistently more moisture than the uncoated samples. Statistical analysis indicated that there were significant differences in the moisture value of the coated and uncoated samples $(p<0.05)$ at the intervals of 0 to 1 and 1 to 3 days of storage. But no significant difference was observed at interval time 3 to 5 days of storage $(p>0.05)$.

Fig. 2 shows the mean of moisture loss percent of coated and uncoated samples after $0,1,3$ and 5 days at refrigerator storage conditions.

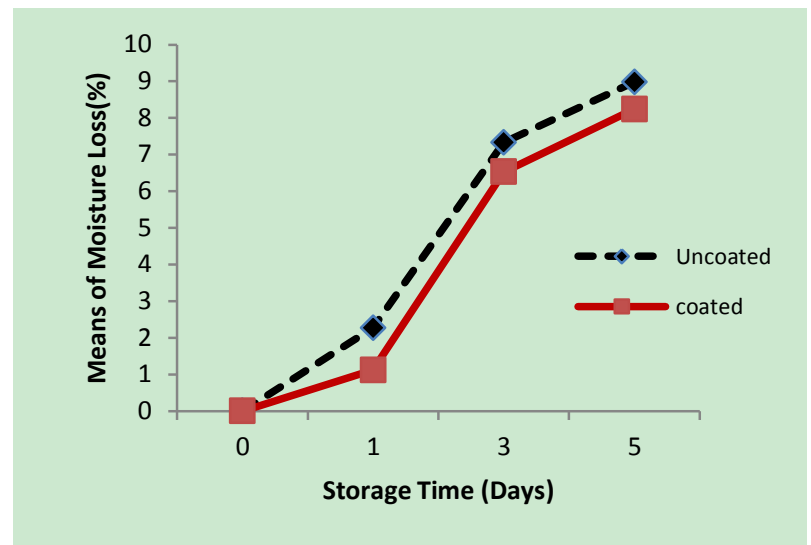

Fig. 2. Mean of moisture loss percents in coated and uncoated samples during 5 days of cold storage.

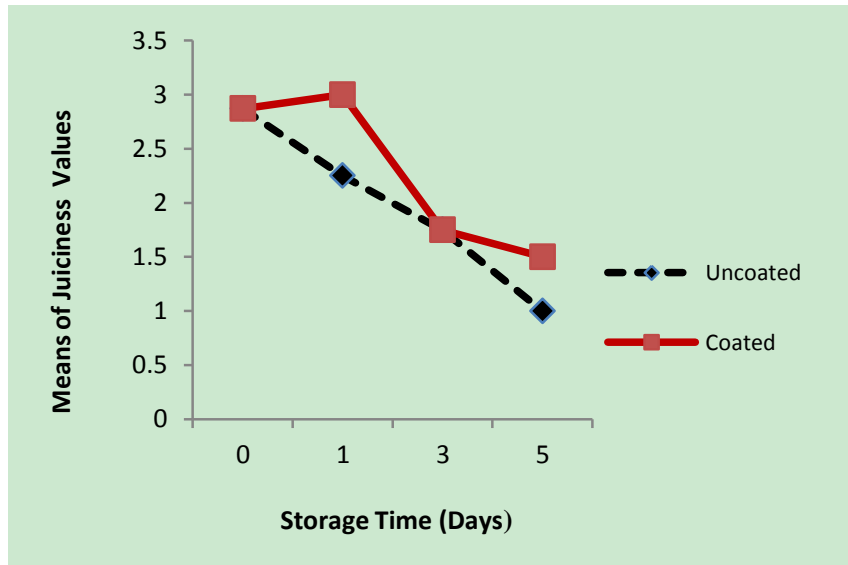

Fig. 3. Mean of juiciness values in coated and uncoated samples during5 days of cold storage.

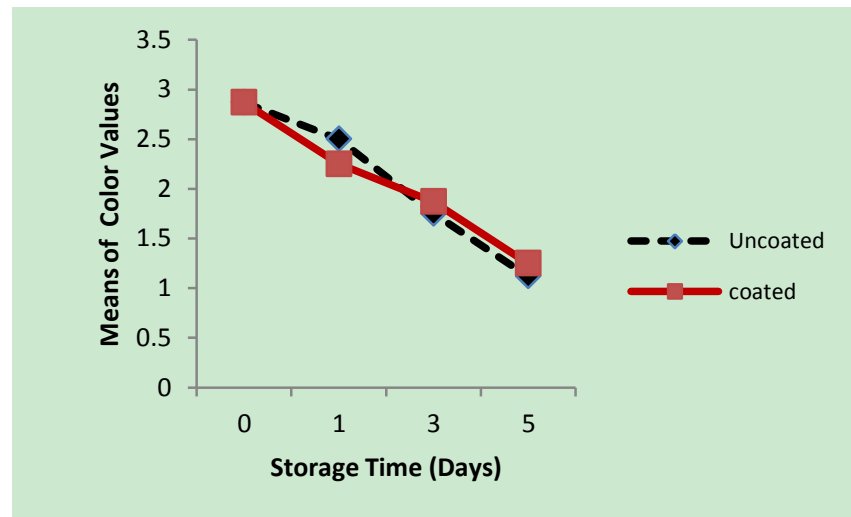

Fig. 4. Mean of color values in coated and uncoated samples during 5 days of cold storage.

The results obtained for moisture loss rate percent in the coating and uncoated samples after $0,1,3$ and 5 days of storage on refrigerator showed that moisture loss percent of coating samples was lower than the uncoated samples. Thus edible coatings were effective in reducing moisture loss 
$(\mathrm{p}<0.05)$. But no significant differences were observed between coated and uncoated samples on the 5 days storage. On the other hand, edible coatings were effective in reducing the moisture loss up to the third day of storage. Fig. 3-5 show the means of juiciness, color and odor values of the coated and uncoated samples during $0,1,3$ and 5 days of refrigerator storage.

The coated samples had consistently more juiciness and colored values during the storage than the uncoated samples. The results obtained from variance analysis showed that there are significantly differences in the juiciness and color values of the coated and uncoated samples $(p<0.05)$. Statistical analysis also indicated that there are significant differences in the juiciness and color values of the coated and uncoated samples $(p<0.05)$ at the interval of 0 to 1 and 1 to 3 days storage, but no significant differences was found at the interval of 3 to 5 days of storage $(p>0.05)$ Variance analysis showed no significant differences in the odor value of the coated and uncoated samples $(p>0.05)$. So, edible coating did not significantly $(p>0.05)$ influence on the odor values of fresh meat.

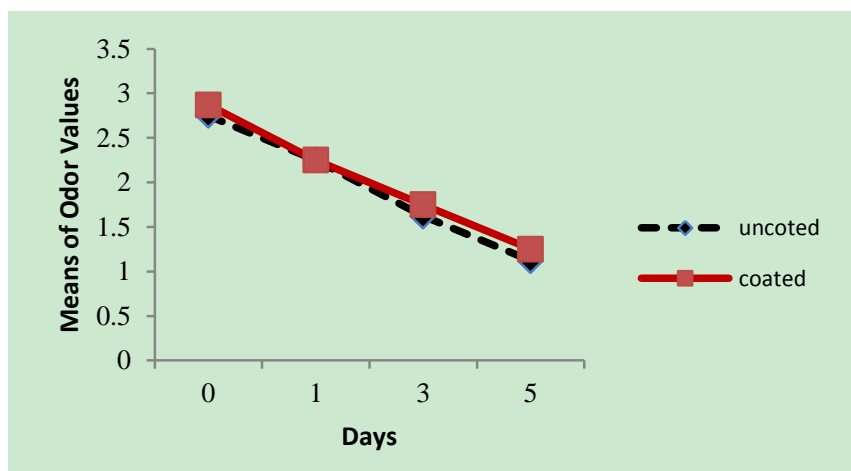

Fig. 5. Mean of odor values in coated and uncoated samples during5 days of cold storage.

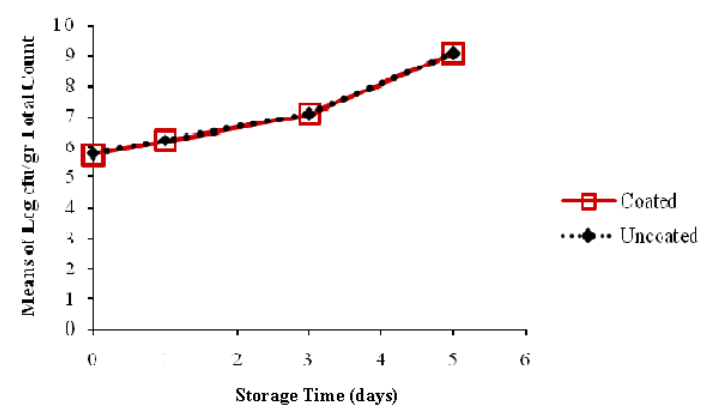

Fig. 6. Mean of $\log$ CFU/g values for the total microbial count of coated and uncoated samples after $0,1,3$ and 5 days of cold storage.

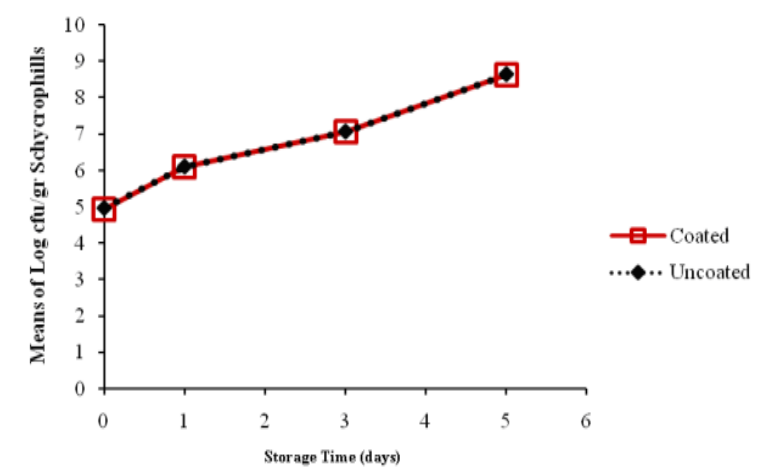

Fig. 7. Mean of $\log \mathrm{CFU} / \mathrm{g}$ values for the psychrophilic bacteria count of coated and uncoated samples after $0,1,3$ and 5 days of cold storage.
Fig. 6 and Fig. 7 show the mean of $\log$ CFU/g values for the total microbial and psychrotrophic micro-organisms count of coated and uncoated samples after 0, 1, 3 and 5 days at refrigerator storage conditions.

The results obtained from variance analysis showed no significant differences in total count and psychrophilic bacteria of coated and uncoated samples $(p>0.05)$.Although, the coating samples were consistently inclined to lower microbial load. Although, the coating samples were consistently inclined to lower microbial load, but edible coating did not significantly $(p>0.05)$ influence on the microbial count of fresh meat. At 5 days storage conditions, the coated samples had higher psychrophilic microbial count than the allowed limit (exceeds $10^{7} \mathrm{CFU} / \mathrm{g}$ ). This would suggest that bacteria off-flavor and drip which developed during the weighing of uncoated meat samples. Therefore, the shelf-life of coated meat was through 3 days storage when compared to the uncoated samples.

Fig. 8 shows the mean total volatile nitrogen (TVN) values of the coated and uncoated samples after $0,1,3$ and 5 days of refrigerator storage.

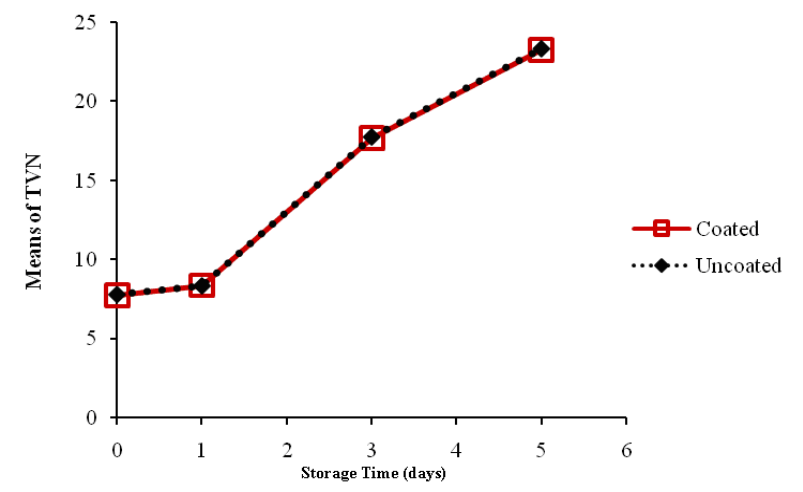

Fig. 8. Mean of the total volatile nitrogen (TVN) values of coated and uncoated samples after $0,1,3$ and 5 days of cold storage.

Variance analysis showed that there are no significantly differences in the mean of total volatile nitrogen (TVN) values of coated and uncoated samples $(p>0.05)$. Evaluation of the effect whey protein coating on the total volatile nitrogen showed that the coated and uncoated samples had no consistent difference in this regard. Although the TVN values of coated samples consistently inclined to lower but edible coating had not significant influence on their TVN values $(p>0.05)$. Since TVN index has been proposed as a method for the assessment of the spoilage of fresh meat, most meats can be considered as acceptable if their TVN values do not exceed $16.5 \mathrm{mg} \mathrm{N} / 100 \mathrm{~g}$. In this study, the mean of TVN value was $16 \mathrm{mg} \mathrm{N} / 100 \mathrm{~g}$ at the 5 days refrigerator storage conditions. A correlation between TVN and log of bacterial count was not significantly different. Limited moisture barrier ability of protein-based coating is mainly due to the hydrophilic nature of proteins.

\section{CONCLUSION}

Therefore it can be concluded that whey protein coating showed acceptable effect on the quality properties of meats in terms of moisture content, moisture loss, color and juiciness and overall appearance as compared the uncoated and control samples which had been stored in retail plastic trays at 3 days 
of storage. Edible coating could enhance product presentation and eliminate the need for placing absorbent pads at the bottom of the trays. The results of this study showed that the effect of whey protein edible coating on the microbial properties and total volatile nitrogen of meat during $0,1,3$ and 5 days storage conditions had no significant different $(p>0.05)$. The barrier of protein coating is affected by water absorption. Therefore, the relative humidity (RH) can substantially affect coating properties. The increase of permeability may be related to the hydrophilicity of whey protein. Interactions between water molecules and amide groups contribute to higher water content in the coating as well as to a modification of the protein network structure. Disruption of hydrogen bonds may create additional sites for dissolution of oxygen and increase mobility of the gas molecules within the polymer bulk phase. An edible coating may be used as a vehicle for incorporating food additives such as antioxidants and antimicrobial agents on to the surface of the food, where deterioration of many solid foodstuffs by microbial growth or oxidation begins. Therefore, the inclusion of a preservative in an edible coating enrobed on to the product positions the preservative at the point of the food's greatest susceptibility to deterioration. While edible coatings can be effectively used as carrier of food additives, it is important to remember that these additives may alter adversely the coating's resistance to vapor, gas or solute transport. The influence of a given additive on coating properties will depend on its concentration, its chemical structure, its degree of dispersion and the extent of its interaction with the food.

\section{REFERENCES}

[1] C. N. Cutter, "Opportunities for bio-based packaging technologies to improve the quality and safety of fresh and further processed muscle foods," Journal of Meat Science, vol. 47, pp. 131-142, 2006.

[2] K. S. Miller, M. T. Chiang, and J. M. Krochta, "Heat curing of whey protein films," Journal of Food Science, vol. 62, pp. 1189-1193, 1997.

[3] T. H. McHugh and J. M. Krochta, "Sorbitol - vs Glycerol - plasticized whey protein edible films: Integerated oxygen permeability and tensile property evaluation," Journal of Agricultural and Food Chemistry, vol. 42, pp. 841-845, 1994.

[4] M. B. Perez-Gago and J. M. Krochta, "Denaturration time and temperature effects on solubility, tensile properties and oxygen permeability of whey protein edible films," Journal of Food Science, vol. 66, pp. 705-710, 2001.

[5] M. Anker, J. Berntsen, A. M. Hermansson, and M. Stading, "Improved water vapor barrier of whey protein films by addition of an acetylated monoglyceride," Innovative Food Science \& Emerging Technologies, vol. 3, pp. 81-92, 2002.

[6] J. Oses, I. Fernandez-Pan, M. Mendoza, and J. I. Mate, "Stability of mechanical properties of edible films based on whey protein," 2007.
[7] Institute of Standards and Industrial Research of Iran, Meat and Meat Products Sampling Methods, $1^{\text {st }}$ ed. Revision, ISIRI 690, 2002.

[8] Institute of Standards and Industrial Research of Iran, Meat and Meat Product Preparing Sample, $1^{\text {st }}$ ed. Revision, ISIRI 691, 1972.

[9] F. Lu, D. H. Liu, and X. Q. Ye, "Alginateecalcium coating incorporating nisin and EDTA maintains the quality of fresh northern snakehead (Channa argus) fillets stored at 4_C," Journal Science Food Agriculture, vol. 89, pp. 848-854, 2009.

[10] R. G. Bell, "The retail display life of steaks prepared from chilled-stored vacuum and carbon dioxide packed sub primal beef cuts," Journal of Meat Science, vol. 42, pp. 165-178,1996.

[11] C. O. Gill and T. Jones, "The display of retail packs of ground beef after their storage in master packaging under various atmosphere," Meat Science, vol. 37, pp. 281-295, 1994.

[12] M. E. Zabik and L. E. Dawson, "The acceptability of cooked poultry protected by an edible acetylated monoglyceride coating during fresh and frozen storage," Food Technology, pp. 87-91, 1963.

[13] Institute of Standards and Industrial Research of Iran, Meat and Meat Products Preparing Sample and Total Microorganisms Count, $1^{\mathrm{st}} \mathrm{ed}$. Revision, ISIRI 356, 1996.

[14] Institute of Standards and Industrial Research of Iran, Food Microbiology Method for Total Count at $30^{\circ} \mathrm{C}, 1^{\text {st }}$ edition revision, ISIRI 5272, 2006

[15] Institute of Standards and Industrial Research of Iran, Food Microbiology Methods for Total Psychotrophilic Count, $1^{\text {st }}$ edition revision, ISIRI 2629, 2002.

[16] P. Cunnia, Official Method Analysis of AOA International, vol. 39, pp. 5-6, 1995.

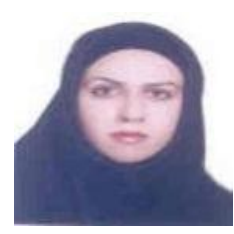

Saba Belgheisi was born in Iran in 1982. She studied for the BSc degree of food science and technology in Iran (Tehran) at Shahid Beheshti Medical Science of University in 2006 and immediately after that she received her MSc degree of food science and technology at the same university. She passed MSc with good grade as a top student.

Now, she is working at Standard Research Center in Iran as a faculty member of Food Science and Technology Department.

Ms. Saba Belgheisi is a member of Food Science Society in Iran and APCBEES.

Reza Soltani was born in Iran in 1983. He studied for the BSc degree of veterinary laboratory science in Iran (Kerman) at Shahid Bahonar University. Now, He is an MSc student of veterinary parasitology. He is working at Standard Research Center in Iran as an expert of Biology Department.

Ramona Massoud was born in Iran in 1980. She studied for BSc degree of food science and technology in Iran (Tehran) at Azad University Science and Research Branch in 2004 and after that she received her MSc degree of food science and technology at the same university. She passed MSc with good grade as a top student.

Now, she is working at Food Science and Technology Department of Standard Organization in Iran. Ms. Ramona Massoud is a member of food Science Society in Iran and APCBEES. 